\title{
Sistema de Comando de Incidentes e comunicação de risco: reflexões a partir das emergências nucleares
}

\author{
Incident Command System and risk communication: reflections from \\ nuclear emergencies
}

Mario Theophilo da Rocha Santos ${ }^{1}$, Marcos Vinicius de Castro Silva², Telma Abdalla de Oliveira Cardoso ${ }^{2}$

DOI: 10.1590/0103-11042020E207

RESUMO Usinas nucleares são projetadas com sistemas dedicados a oferecer um alto grau de proteção aos seus trabalhadores, à população e ao meio ambiente. Entre os níveis de proteção da população e do meio ambiente, encontra-se o plano de emergência nuclear. Este plano deve conter um segmento específico relacionado com o gerenciamento da comunicação de risco à população. Historicamente, técnicas de comunicação de risco surgiram para minimizar danos às pessoas, por meio de estratégias de controle de pânico da população. Entretanto, essa questão atualmente é pouco desenvolvida no Brasil na área de segurança nuclear. Dessa forma, este trabalho visou estabelecer uma proposta inicial no uso da teoria de Sistema de Comando de Incidentes como estratégia de gerenciamento da comunicação de risco em caso de acidentes na Central Nuclear Almirante Álvaro Alberto, localizada no Brasil.

PALAVRAS-CHAVE Gestão da informação. Organizações de planejamento e atendimento a desastres. Centro de controle de emergência nuclear. Centrais nucleares.

\begin{abstract}
Nuclear power plants are designed with systems dedicated to offering a high degree of protection to their workers, the population, and the environment. Between the levels of protection of the population and the environment, there is the nuclear emergency plan. This plan must contain a specific segment related to the management of risk communication to the population. Historically, risk communication techniques have emerged to minimize harm to people, through population panic control strategies. However, this issue is currently underdeveloped in Brazil in the field of nuclear safety. Thus, this work aimed to establish an initial proposal on the use of the theory of Incident Command System as a strategy for managing risk communication in the event of accidents at the Almirante Álvaro Alberto Nuclear Power Plant located in Brazil.
\end{abstract}

KEYWORDS Information management. Organizations for planning and care in disasters. Nuclear emergency control center. Nuclear power plants.

\footnotetext{
1 Secretaria de Estado da Defesa Civil (SEDC) - Rio de Janeiro (RJ), Brasil. theophilo@globo.com

2 Fundação Oswaldo Cruz (Fiocruz), Escola Naciona de Saúde Pública Sergio Arouca (Ensp) - Rio de Janeiro (RJ), Brasil.
} 


\section{Introdução}

O uso pacífico da energia termonuclear prescreve uma série de critérios de segurança para proteção da saúde coletiva, minimização do risco à vida e à propriedade.

Usinas nucleares caracterizam-se pelo uso de materiais radioativos que produzem calor por meio de uma reação nuclear, o qual é empregado por um ciclo termodinâmico convencional para mover um alternador e produzir energia elétrica. Entre as principais causas de acidentes postulados para uma central nuclear, estão: perda de refrigerante do sistema primário, ruptura de tubos do trocador de calor, ruptura de tubo da linha de vapor do sistema secundário e acidentes envolvendo o manuseio de combustível. Fatores organizacionais, deficiências de projeto, degradação dos sistemas por envelhecimento, perda da integridade das barreiras de contenção, formação inadequada de pessoal, falhas de equipamentos, inexperiência operacional, formulação inadequada de procedimentos, gerenciamento de rejeitos e causas externas são fatores que podem gerar um evento desencadeador ${ }^{1}$. Em muitos casos, os acidentes se devem à combinação de diversos fatores.

Acidente nuclear é um sinistro de pequena probabilidade de ocorrência, entretanto, produz consequências imprevisíveis em todos os níveis e, provavelmente, com desdobramentos de repercussão internacional, razão pela qual existe um rígido controle efetuado por órgãos regulatórios de governos, agências internacionais e sociedade civil organizada ${ }^{2}$.

Um dos problemas observados na quantidade de vítimas produzidas nesses tipos de acidentes é o alargamento das fronteiras primárias do acidente, fruto da falta de coordenação e gerenciamento da qualidade da comunicação com a população, da produção de notícias falsas ou meias-verdades, da manipulação de dados e, principalmente, da falta de uma orientação clara na condução das incertezas que emergem do desastre. Todos esses fatores trazem consigo o pânico que pode gerar efeitos colaterais, produzindo um número de vítimas maior que a causa do próprio acidente ${ }^{3}$.

Destarte, este estudo visa propor uma estratégia de aperfeiçoamento das estruturas de resposta à emergência nuclear no Brasil, a fim de contribuir para a melhoria do planejamento de resposta à emergência nuclear e da gestão da comunicação de risco utilizando a teoria do Sistema de Comando de Incidentes (Incident Command System - ICS).

\section{Retrospectiva histórica das emergências nucleares a partir da comunicação de risco}

Durante os acidentes radiológicos e nucleares, a biossegurança tem como uma de suas estratégias para a proteção da população ações de prevenção e contenção que produzam menor tempo de exposição, maior distância da fonte e blindagem. Dessa forma, a evacuação da população para longe do sítio do sinistro (distância), de modo rápido (tempo), para abrigos seguros (blindagem), é a forma utilizada convencionalmente para protegê-la. Entretanto, existem outros fatores que podem aumentar o número de vítimas, como, por exemplo, as falhas na comunicação.

Historicamente, observam-se exemplos de problemas no gerenciamento da comunicação de risco durante acidentes envolvendo radioisótopos responsáveis pela produção de efeitos secundários com diferentes gravidades e intensidades, dentre os quais, destacam-se: Three Mile Island (EUA), Goiânia (Brasil), Chernobyl (Ucrânia) e Fukushima (Japão). Esses acidentes tiveram um grau de risco entre 5 e 7 , respectivamente, segundo a Escala de Eventos Nucleares ou International Nuclear and Radiological Event Scale (Ines) ${ }^{4}$. Essa Escala foi desenvolvida em 1990 por especialistas a partir da necessidade de comunicar a importância de qualquer evento relacionado com a operação de instalações 
nucleares ou com a condução de atividades que possam originar riscos de radiação à população. A Ines é, portanto, uma escala internacional de classificação de eventos semelhante a escalas já usadas em outras áreas, como as que comparam a severidade dos terremotos. O seu uso pode facilitar um entendimento comum entre os técnicos, a mídia e o público.
Os eventos são classificados na escala em sete níveis: os níveis 4-7 são denominados 'acidentes', e os níveis 1-3, 'incidentes'. Eventos sem importância para a segurança são classificados como 'abaixo da escala' ou nível 0 . Eventos que não têm relevância de segurança com em relação à radiação ou segurança nuclear não são classificados na escala. A estrutura da Ines é mostrada no quadro 1.

Quadro 1. Critérios para classificar os eventos

\begin{tabular}{|c|c|c|c|}
\hline Descrição Nível & Saúde e meio ambiente & Impacto nas instalações & Defesa \\
\hline $\begin{array}{l}\text { Acidente grave } \\
\text { Nível } 7\end{array}$ & $\begin{array}{l}\text { Grande liberação de material radioativo } \\
\text { com efeitos ambientais e de saúde gene- } \\
\text { ralizados, exigindo a implementação de } \\
\text { medidas planejadas e estendidas. }\end{array}$ & - & - \\
\hline $\begin{array}{l}\text { Acidente sério } \\
\text { Nível } 6\end{array}$ & $\begin{array}{l}\text { Liberação significativa, que requer a im- } \\
\text { plementação de medidas planejadas. }\end{array}$ & - & - \\
\hline $\begin{array}{l}\text { Acidente com } \\
\text { consequências } \\
\text { amplas } \\
\text { Nível } 5\end{array}$ & $\begin{array}{l}\text { Liberação limitada com possibilidade } \\
\text { de implementação de medidas parciais } \\
\text { planejadas. Várias mortes por radiação. }\end{array}$ & $\begin{array}{l}\text { Danos graves no núcleo do reator. Libera- } \\
\text { ção de grandes quantidades de material } \\
\text { radioativo dentro de uma instalação. Pode } \\
\text { ser resultante de um grande acidente ou } \\
\text { incêndio. }\end{array}$ & - \\
\hline $\begin{array}{l}\text { Acidente com } \\
\text { consequências } \\
\text { locais Nível } 4\end{array}$ & $\begin{array}{l}\text { Pequena liberação com improvável im- } \\
\text { plementação de medidas planejadas, a } \\
\text { não ser as de controles locais. Pelo menos } \\
\text { uma morte por radiação. }\end{array}$ & $\begin{array}{l}\text { Derretimento do combustível ou dano } \\
\text { ao combustível, resultando em mais de } \\
\text { 0,1\% de liberação do estoque principal. } \\
\text { Liberação de quantidades significativas de } \\
\text { material radioativo dentro de uma instala- } \\
\text { ção com alta probabilidade de exposição } \\
\text { pública. }\end{array}$ & - \\
\hline $\begin{array}{l}\text { Incidente grave } \\
\text { Nível } 3\end{array}$ & $\begin{array}{l}\text { Exposição superior a dez vezes o limite } \\
\text { anual legal para trabalhadores. Efeito não } \\
\text { letal na saúde (p.ex. queimaduras). }\end{array}$ & $\begin{array}{l}\text { Dispersão grave com taxas superiores a } \\
1 \mathrm{~Sv} / \mathrm{h} \text { em uma área operacional. Efeitos } \\
\text { agudos na saúde de um trabalhador, com } \\
\text { baixa probabilidade de exposição pública. }\end{array}$ & $\begin{array}{l}\text { Quase acidente em uma usina nuclear, } \\
\text { perda total das barreiras de segurança. } \\
\text { Roubo ou perda de fonte selada altamente } \\
\text { radioativa. Fonte lacrada altamente ra- } \\
\text { dioativa, sem procedimentos de radiação } \\
\text { adequados. }\end{array}$ \\
\hline $\begin{array}{l}\text { Incidente } \\
\text { Nível } 2\end{array}$ & $\begin{array}{l}\text { Exposição de um público em excesso de } \\
10 \text { mSv. Exposição de um trabalhador } \\
\text { acima dos limites anuais legais. }\end{array}$ & $\begin{array}{l}\text { Níveis de radiação de mais de } 50 \text { mSv/h. } \\
\text { Contaminação significativa dentro da } \\
\text { instalação. }\end{array}$ & $\begin{array}{l}\text { Falhas significativas nas barreiras de se- } \\
\text { gurança. Fonte órfã selada, ou dispositivo } \\
\text { de transporte, altamente radioativo, com } \\
\text { dispositivos de segurança intactos Emba- } \\
\text { lagem inadequada de uma fonte selada } \\
\text { altamente radioativa. }\end{array}$ \\
\hline $\begin{array}{l}\text { Anomalia } \\
\text { Nível } 1\end{array}$ & - & - & $\begin{array}{l}\text { Exposição de uma pessoa acima dos } \\
\text { limites. Pequenos problemas nas barreiras } \\
\text { de segurança. Fonte radioativa, dispositivo } \\
\text { de transporte de baixa atividade perdidos } \\
\text { ou roubados. }\end{array}$ \\
\hline
\end{tabular}

Fonte: Adaptado de IAEA4. 


\section{Acidente de Three Mile Island}

Em 28 de março de 1979, próximo à cidade de Harrisburg, na Pensilvânia, aconteceu o mais grave acidente nuclear dos Estados Unidos da América (EUA), envolvendo um reator nuclear refrigerado à água leve pressurizada (modelo PWR), da Unidade II, com capacidade de geração de $900 \mathrm{MW}$, da Central Nuclear de Three Mile Island (TMI). O acidente foi causado por falha técnica do equipamento, seguido de uma falha humana na avaliação das condições do reator ${ }^{5}$.

A falha de equipamento causou uma perda gradual da água de resfriamento no núcleo do reator, resultando em fusão parcial das varetas do elemento combustível e urânio, provocando a liberação de material radioativo para fora do núcleo. Segundo análise da agência regulatória americana (United States Nuclear Regulatory Commission ou U.S.NRC) a respeito do acidente, houve falhas na comunicação entre os técnicos da Usina e as autoridades do escritório central da U.S.NRC em Washington. Informações incompletas e discrepantes chegavam à capital e evidenciaram, desde os primeiros momentos, que as decisões deveriam ser tomadas no sítio da instalação, e não em Washington. Uma medida de valor alto de radiação tomada no interior da Usina (12 rem/h) foi interpretada na capital como dose ambiental. Tal fato originou pânico e desencadeou a evacuação da população até um raio de $32 \mathrm{~km}$ ao redor da usina, abrangendo uma população de 625 mil pessoas $^{6}$.

O plano de emergência vigente previa a evacuação da população em um raio de apenas $8 \mathrm{~km}$. Assim, acidentes de trânsito, engarrafamentos e diversas pessoas foram vítimas secundárias devido à falta ou desencontro de informações 5 .

Sandman 7 relatou que, apesar de haver a identificação da unidade de comando, houve uma falta de definição na matriz de responsabilidades, falta de comunicação entre as autoridades, outras agências responsáveis e o público; bem como uma equipe previamente preparada para a organização de ações de minimização de pânico.

A mídia, por desconhecer as informações sobre os efeitos da radiação e as terminologias técnicas, não conseguiu perceber a gravidade da situação devido à utilização exacerbada de termos técnicos utilizados na comunicação com a imprensa. Durante o acidente, a equipe técnica ocupada em resolver a situação de emergência evitava falar com a imprensa, obrigando repórteres a buscar informações de fontes não oficiais ${ }^{8}$. Assim, as notícias que chegavam à população provinham de diversas áreas e de diferentes pessoas, causando uma situação de confusão e desconfiança.

Meses após o acontecimento, Collins et al. ${ }^{9}$ ressaltaram efeitos persistentes à saúde da população afetada, tais como: aumento do risco de depressão e ansiedade e o acréscimo de sintomas.

\section{Acidente na Central Nuclear de Chernobyl}

Em 25 de abril de 1986, antes de uma parada projetada da unidade IV da Central Nuclear de Chernobyl, na Ucrânia, antiga União Soviética, técnicos da operação resolveram romper com os protocolos de segurança vigentes e realizar uma experiência destinada a testar se a refrigeração do núcleo do reator estaria garantida, caso houvesse perda de energia externa.

O teste objetivava verificar se o turbo gerador, após a condição de desligado a quente (corte de fonte externa e geração de energia interna por inércia), proveria energia suficiente para manter as bombas de água de circulação em funcionamento, mantendo uma margem segura de refrigeração do reator, enquanto os geradores diesel de emergência não entrassem em serviço. Para realizar esse teste, os operadores, autorizados pelo chefe de engenharia, deveriam reduzir a potência de saída do reator de forma gradativa e dentro de um intervalo de tempo adequado para um valor mais seguro, segundo os regulamentos de segurança. Porém, devido à demora em iniciar o teste, a queda de 
potência se deu muito rapidamente e próximo ao valor seguramente permitido. Essa falha humana demonstrou um deficit na observância das normas de segurança, resultando em um dos piores acidentes nucleares da história ${ }^{3,10,11}$.

O balanço dos danos do acidente contabilizou 237 pessoas atingidas, sendo que 134 foram gravemente expostas ou contaminadas; 32 mortes imediatas, a maioria como resultado de queimaduras térmicas e de radiação entre os trabalhadores e outros que tentaram apagar o fogo. Um total de 143 operários e bombeiros desenvolveram síndrome de radiação aguda, dos quais 31 morreram em 3 meses (28 morreram de supressão da medula óssea ou dano gastrointestinal) ${ }^{\mathbf{1 2}}$.

Após 20 anos do acidente, em 2006, iversas agências da Organização das Nações Unidas reuniram-se para avaliar os impactos sobre os principais países afetados: Rússia, Ucrânia e República de Belarus. O estudo resultante desse encontro evidenciou que, paralelamente às mortes e doenças causadas pela radiação, $o$ impacto na saúde mental foi o maior problema em saúde pública causado pelo acidente. A falta de informação, a quantidade de rumores e o pânico gerado produziram danos à população afetada, que são sentidos até os dias atuais ${ }^{3}$.

Vários autores $\mathbf{7 , 1 1 , 1 3}^{13}$ relataram a inexistência de um plano de resposta à emergência nuclear. O governo, juntamente com a força tarefa, ficou responsável por gerenciar as consequências do acidente, não havendo a formação de um centro de comunicações de incidentes. As informações eram restritas e demoraram a chegar à população. Rubin ${ }^{\mathbf{1 3}}$ relatou que elas só chegaram à população quando a crise não podia ser mais controlada. As primeiras notícias foram anunciadas por uma rádio local, no início da evacuação de Pripyat, cerca de 36 horas depois do evento.

Assim como no acidente de Three Mile Island, em que as informações provinham de diferentes fontes áreas; em Chernobyl, essas fontes eram quase inteiramente provenientes dos EUA e da Europa Ocidental. Fontes do bloco soviético raramente eram ouvidas.
Os soviéticos permaneceram inertes quanto à comunicação de risco, dando chances às especulações ${ }^{12}$.

\section{Acidente radiológico de Goiânia}

No final de 1985, um instituto particular de radioterapia, em Goiânia, Brasil, mudou-se para novas instalações, deixando uma unidade de radioterapia contendo uma cápsula de Césio-137, sem notificar a autoridade de licenciamento, conforme exigido nos termos da licença do instituto. Posteriormente, as antigas instalações foram parcialmente demolidas.

Em 13 de setembro de 1987, esse equipamento foi violado por duas pessoas, na intenção de aproveitar o material da contenção para vendê-lo. Removeram a montagem da fonte da cabeça de radiação da máquina, levaram para casa e tentaram desmanchar. A fonte radioativa estava na forma de sal de cloreto de césio, que é altamente solúvel e prontamente dispersivo. Os restos da montagem da fonte foram vendidos como sucata ao dono de um ferro-velho. Atraídos pela luminescência do césio, várias pessoas ficaram fascinadas; e, durante um período de dias, amigos e parentes vieram para ver o fenômeno. Fragmentos da fonte foram distribuídos. O material acabou espalhado em diversas residências e locais públicos. Isso ocorreu por cinco dias, período em que várias pessoas apresentavam sintomas gastrointestinais decorrentes da exposição à radiação da fonte.

Os primeiros sintomas da contaminação (náuseas, vômitos, tonturas, diarreia) apareceram algumas horas após o contato com o material. As pessoas procuravam serviços de saúde, sendo diagnosticadas como vítimas de alguma doença infectocontagiosa. Após 15 dias do desmanche do aparelho, um físico local detectou na amostra, que se encontrava na Coordenadoria de Vigilância Sanitária da Secretaria de Saúde local, a emissão de radiação, concluindo que os sintomas dos atingidos eram da Síndrome Aguda da Radiação ${ }^{\mathbf{1 4}}$; e alertou a Comissão Nacional de Energia 
Nuclear (CNEN). Reconhecendo a gravidade do incidente, a CNEN solicitou ajuda da International Atomic Energy Agency (AIEA). As autoridades estabeleceram uma área de triagem para pessoas contaminadas no estádio olímpico, onde foram improvisadas barracas para alojamento. Naquela noite, equipes de emergência isolaram e evacuaram vários quarteirões da cidade. Dessa forma, 112.800 pessoas foram monitoradas dosimetricamente. Identificaram-se 249 pessoas com nível de contaminação acima do normal, 20 foram hospitalizadas, sendo que 1 delas teve o antebraço direito amputado, e 4 foram a óbito. Em meio a isso tudo, após a morte das 2 primeiras vítimas, médicos patologistas do hospital de referência na cidade recusaram-se a realizar as necropsias devido ao risco de contaminação e exposição $0^{15}$.

As autoridades brasileiras não divulgaram declarações oficiais ou outras informações ao público enquanto realizavam as operações de resposta. Rumores se espalharam pela cidade, o que levou alguns repórteres e o público a convergirem para o estádio olímpico em busca de informações. Essa carência de informações deu asas à imaginação e fomentou o medo do desconhecido, causando pânico entre os agentes de saúde, agentes de segurança e população, que, a todo custo, queriam sair desordenadamente das regiões próximas ao acidente ${ }^{\mathbf{1 4 , 1 6}}$. Apesar dos rumores e da crescente agitação social, os funcionários do governo não estabeleceram mecanismos de comunicação para responder a perguntas e informar o público.

A vestimenta dos técnicos em radiologia da agência do governo federal, encarregados da monitoração das pessoas e do ambiente, bem como seus equipamentos, produziam medo nas pessoas. As máscaras faciais dificultavam o entendimento da fala dos profissionais. A abordagem era fria e não havia interlocutores entre a área técnica e a população.

Ressalta-se que o Brasil possuía uma estrutura para lidar com emergências radiológicas ou nucleares. Na época do acidente, essa estrutura era formada por: 1) plano de emergência para acidentes ocorridos em instalações nucleares
(Central Nuclear Almirante Álvaro Alberto CNAAA, localizada em Angra dos Reis); e 2) plano de resposta para lidar com instalações não nucleares; que, na percepção dos responsáveis pela elaboração, poderiam estar associados aos acidentes de menor escala, como acidentes de transporte ou em instalações de radiografia ${ }^{\mathbf{1 4}}$. Porém, Goiânia não se adequava a essa estrutura. No entanto, o coordenador de emergência da CNEN utilizou a experiência do acidente radiológico ocorrido em 1983, na cidade de Juarez, no México, que possuía características similares. Apesar de não haver uma cadeia de comando predefinida para essa situação, havia um plano de emergência ${ }^{\mathbf{1 4}}$.

Somente nas semanas seguintes ao acidente as autoridades de Goiânia desenvolveram um programa público de comunicação, na tentativa de corrigir a desinformação e restabelecer a confiança do público. Eles distribuíram 250 mil cópias de um panfleto, orientando a respeito da radioatividade e da radiação, em um esforço para limitar a desinformação. Eles também estabeleceram um número telefônico para responder às perguntas ou receber informações sobre possíveis contaminações ${ }^{\mathbf{1 5}}$. Porém, a cidade ficou sitiada por preconceitos da sociedade externa àquela realidade local ${ }^{14}$. O dano social perdurou durante muito tempo para a população, que não obteve nenhum suporte das autoridades, até porque estes não estavam preparados para responder a um acidente daquela natureza. As consequências psicológicas do acidente, a exemplo do que aconteceu em Chernobyl ${ }^{3}$, foram muito mais abrangentes do que a própria contaminação pelo Césio-137. Como consequência, a população sofre problemas de ordem psicológica e psicossomática até os dias atuais ${ }^{16,17}$.

\section{Acidente nuclear de Fukushima}

O acidente na Central Nuclear de Fukushima, ocorrido em 11 de março de 2011, foi considerado um desastre nuclear, que foi causado pelo derretimento do núcleo de três dos seis reatores nucleares da usina. A falha ocorreu 
quando a usina foi atingida por um tsunami secundário a um terremoto de magnitude 8,9 na escala Richter. Devido ao colapso de uma torre de energia, houve a interrupção do fornecimento de eletricidade à estação, gerando falta de arrefecimento dos reatores pela água. Os quais, mesmo desativados, aqueceram, levando a uma fusão parcial do núcleo nos reatores I, II e III. O fato foi agravado pela formação do gás hidrogênio, causando uma explosão que destruiu o revestimento superior de concreto dos edifícios de alojamento dos reatores I, III e IV. No reator II, a explosão provocou a exposição do núcleo. Iniciou-se, no reator IV, uma série de incêndios. Dessa forma, houve liberação de quantidades importantes de material radioativo para o meio ambiente, notadamente iodo e césio, contaminando o ar, o solo e a água ${ }^{18}$.

Após 30 horas do início do desastre, o primeiro-ministro japonês Kan Naoto dirigiu-se à população para tratar do terremoto e do tsunami que atingira Tóquio e a metade norte da ilha principal do Japão. Entretanto, o próprio ministro não tinha conhecimento da gravidade do acidente em curso ${ }^{18}$. A companhia de energia elétrica de Tóquio (TEPCO), que operava a Central Nuclear de Fukushima, fiscalizada pelo órgão regulatório japonês denominado Japan's Nuclear and Industrial Safety Agency (Nisa), não informara ao governo o que estava acontecendo. Somente cinco dias após o início do desastre o primeiro-ministro, depois de uma visita à Central Nuclear, ficou ciente da gravidade dos fatos. Em face dessa situação, a população ficou exposta aos riscos durante cinco dias, preocupada exclusivamente com o tsunami e com o terremoto. Posteriormente à constatação, o ministro dirigiu-se ao povo japonês alertando sobre os riscos de contaminação e de exposição radiológica, bem como para novos vazamentos de radiação na central nuclear. Naquela ocasião, o ministro optou por estender o raio de exclusão de 20 quilômetros, antes previsto no planejamento, para um raio de 30 quilômetros da planta de Fukushima, recomendando a todos que permanecessem dentro de casa. Somente após essa ação, as autoridades começaram a explicar à população e ao resto do mundo a gravidade em Fukushima' ${ }^{19}$.

Seis dias após o acidente, vários países criticaram a gestão da informação no Japão. A AIEA, à qual o Japão é afiliado, protestou publicamente sobre a impropriedade da ação japonesa. As medições de radiação em um raio de 50 quilômetros do sítio da central nuclear, na parte norte do Japão, apresentaram níveis altos de césio. Alimentos produzidos na área foram proibidos de serem vendidos. O governo recomendou que a água da torneira não deveria ser usada para preparar alimentos. Níveis de contaminação por plutônio foram detectados no solo em dois locais da central nuclear.

Kortov e Ustyantsev ${ }^{\mathbf{2 0}}$ compararam as consequências dos acidentes em Chernobyl e Fukushima (tabela 1). Nesta tabela, observam-se as principais diferenças entre os dois acidentes.

\begin{tabular}{lrr}
\hline Tabela 1. Consequências dos acidentes nas centrais nucleares de Chernobyl e de Fukushima & \\
\hline Acidente & Chernobyl & Fukushima \\
\hline Quantidade de substâncias radioativas liberadas na atmosfera & $5.2 .10 \mathbf{1 8} \mathrm{Bq}$ & $6.3 .10 \mathbf{1 7} \mathrm{Bq}$ \\
Contaminação territorial & $450.000 \mathrm{~km}^{2}$ & $8.000 \mathrm{~km}^{2}$ \\
Contaminação do território de outros países & $250.000 \mathrm{~km}^{2} \mathrm{na}$ & $0 \mathrm{~km}^{2}(a)$ \\
& Europa Ocidental & $1.100 \mathrm{~km}^{2}$ \\
Área de evacuação & $10.800 \mathrm{~km}^{2}$ & 0 \\
Quantitativo de pessoas evacuadas & 400.000 pessoas & 83.000 pessoas \\
Mortalidade por radiação aguda dentro de 4 meses após o acidente & 28 & 0 \\
\hline
\end{tabular}

Fonte: Kortov e Ustyantsev20(15)

(a) $\mathrm{O}$ acidente em Fukushima não causou poluição em outros países. 
A população, apesar de sua cultura resiliente, passou a desconfiar das informações produzidas pelas autoridades, que, desconexas, geravam inquietação. Por meio da imprensa, a população recebia notícias e rumores gerados a partir do crescimento das taxas de radiação mensuradas. Cerca de 15.884 vítimas morreram, fruto do tsunami e do terremoto, $300 \mathrm{mil}$ foram evacuadas; e, destas, 1.600 óbitos foram relacionados com as condições de evacuação ${ }^{18}$.

Embora o Japão tenha produzido mecanismos de respostas aos desastres, dadas as características únicas do evento, o estágio inicial das respostas foi confrontado com circunstâncias que diferiam dos cenários previstos e foram operados de maneira imprevista, assim, inicialmente, não foram utilizadas plenamente as capacidades, o que resultou na inadequação dessas respostas ${ }^{21}$.

Ressalta-se que, no Japão, há uma descentralização das responsabilidades na gestão de crises, incluindo aquelas relacionadas com a segurança nuclear. Na verdade, não existe um sistema unificado para executar as funções de comando e controle. Assim, a partir do estabelecido nos instrumentos legais, o primeiro-ministro ficou no comando, mesmo não desempenhando um papel de integração das instâncias na gestão de crises. Além disso, o conselho de segurança, que deveria ser convocado para deliberar sobre as medidas de gestão de crises, não foi convocado para responder ao acidente devido ao desastre nuclear não ter sido considerado dentro do mandato do conselho de segurança. Por outro lado, no arcabouço político, não existia uma estrutura que pudesse servir de comando de incidentes no lugar do conselho de segurança. Consequentemente, nessa ausência, a tomada de decisões do governo foi conduzida mediante procedimentos ambíguos ${ }^{22}$.

\section{Comunicação de risco}

A teoria da comunicação de risco surgiu para melhorar a maneira de informar sobre os riscos aos quais as pessoas estão expostas. Essa teoria foi motivada principalmente pelo crescimento de acidentes em plantas industriais ${ }^{23}$. Dessa forma, por intermédio de suas agências de controle, os governos passaram a exigir que os planos de emergência das plantas industriais possuíssem um capítulo específico direcionado à gestão e à comunicação de risco.

A comunicação de risco traz à população informações sobre uma condição específica de um desastre ou até sobre transições de estados comportamentais da evolução da situação que ameaça à saúde, à segurança ou ao ambiente. É um processo interativo de troca de informações sobre riscos (natureza, gravidade e aceitabilidade) entre indivíduos, instituições e comunidades. A conscientização depende da informação, dessa forma, a comunicação de risco é a base para a preparação das respostas aos acidentes e emergências. A comunicação no momento da emergência auxilia a população a compreender e a adotar comportamentos de proteção. Permite às autoridades e aos especialistas auscultarem as populações e responderem às suas preocupações e necessidades, para que o aconselhamento seja relevante, confiável e aceitável24.

Em uma emergência radiológica ou nuclear, a comunicação é um dos componentes decisivos para o atendimento aos objetivos da resposta ${ }^{8}$. Mesmo em situações de não emergência, aqueles que podem atuar como primeiros respondedores, como polícia, setor saúde ou defesa civil, passam muito tempo no cotidiano respondendo pedidos de informação em vez de iniciar diálogos com os membros de sua equipe ou alertar o público sobre o risco ${ }^{7,8}$.

A comunicação deve conter mensagens claras e concisas, possuindo um vocabulário que não se distancie do entendimento do receptor com menor formação intelectiva. Mudanças de classe de avisos, na evolução da emergência, devem ser administradas de forma paulatina e cautelosa, possibilitando que os receptores da mensagem consigam processá-la e reagir conforme o protocolo esperado e previamente treinado 25 .

Os protocolos de comunicação de risco devem ser planejados, revisados periodicamente 
e treinados com a sociedade que é alvo de sua construção. As ações planejadas de comunicação de risco devem fugir de modelos que reproduzam a simples informação gerada por especialistas. Devem incluir as dimensões da percepção pública na análise de risco e a interação dos segmentos envolvidos, trazendo maior adesividade às ações planejadas ${ }^{26}$.

Os segmentos envolvidos na comunicação de risco devem possuir critérios de confiança e credibilidade para sua robustez. Esses valores são construídos de modo insidioso e progressivo, utilizando-se de coerência e consistência de ações, competência e ética. Um valor que pode afetar a verdade propalada é a incerteza científica contida no pacote de informação dispensada à população. Não se pode garantir informações que são passíveis de incertezas. É preciso tratar disso na composição da estratégia de comunicação, a fim de não produzir assertivas friáveis ao longo do tempo. Esse tipo de falha de comunicação pode gerar perda da credibilidade e controle da efetividade da comunicação 25 .

\section{Organização atual da resposta a acidentes na Central Nuclear Almirante Álvaro Alberto}

A CNAAA, situada na cidade de Angra dos Reis, no estado do Rio de Janeiro, possui um plano de emergência composto por um conjunto de protocolos e de procedimentos necessários para responder a um acidente nuclear. Entre eles, está previsto o protocolo de acionamento inicial, para o cumprimento das providências estabelecidas pelo Sistema de Proteção ao Programa Nuclear Brasileiro (Sipron), responsável por assegurar o planejamento integrado, estabelecendo estruturas que, ao serem notificadas a respeito de um evento desencadeador de acidente nuclear, devem atuar imediatamente na montagem de estruturas de gerenciamento de resposta, compostas por três centros de coordenação e controle de emergência (nacional, estadual, local), assim como um centro de gerenciamento de informações dedicado à imprensa e à população $0^{27,28}$.

\section{Centro Nacional para Gerenciamento de uma Situação de Emergência Nuclear (CNAGEN)}

Sediado em Brasília, possui a função de assessorar o governo federal sobre a evolução da emergência nuclear, bem como supervisionar e coordenar o apoio dos órgãos federais, entidades públicas e privadas nacionais ou internacionais, das ações suplementares empreendidas e os meios utilizados na resposta a uma situação de emergência nuclear.

\section{Centro Estadual de Gerenciamento de Emergência Nuclear (Cestgen)}

Situado no Departamento Geral de Defesa Civil, na cidade do Rio de Janeiro, é responsável pelo assessoramento das decisões do governo estadual na ocorrência de situações de emergência, além de coordenar o apoio dos órgãos públicos e privados sediados em sua área de influência, complementando as ações empreendidas e os meios utilizados na resposta à emergência nuclear.

\section{Centro de Coordenação e Controle de Emergência Nuclear (CCCEN)}

Localizado em Angra dos Reis (RJ), é responsável por coordenar as ações dos diversos órgãos sediados no município e adjacências, gerenciando a emergência localmente, bem como promovendo o apoio às ações e estratégias de propagação de informações e controle de rumores em caso de uma emergência.

\section{Centro de Informações de Emergência Nuclear (Cien)}

Sediado em Angra dos Reis, responde pela gestão da comunicação de risco, monitoração de rumores, assim como pela difusão de informações ao público e à imprensa.

O Cien é composto por um representante de cada uma das seguintes instituições: Defesa Civil municipal, Defesa Civil estadual, 
Eletronuclear e CNEN. Apesar da paridade propiciar uma representação significativa dos responsáveis pelo controle de pânico na emergência, a estrutura internamente não está organizada, sendo composta por um líder e demais subordinados.

\section{Uso do sistema de comando de incidentes no gerenciamento da comunicação de risco}

O ICS foi desenvolvido a partir de $1970 \mathrm{em}$ resposta aos incêndios florestais no sudoeste da Califórnia ${ }^{29}$. Nestes, diferentes agências dos EUA tiveram que atuar em conjunto, e a avaliação diária das operações evidenciou a falta de uma estrutura de comando clara, dificuldades no estabelecimento de prioridades e objetivos convergentes, inexistência de uma terminologia comum e falta de integração e padronização nas comunicações. O ICS surgiu como uma ferramenta de integração entre agências ${ }^{29}$.

Ele concentra a tomada de decisões das ações de respostas. É uma estratégia padronizada de gerenciamento do incidente no local, com todos os riscos, que permite adotar uma estrutura organizacional integrada para atender às complexidades e às demandas de incidentes únicos ou múltiplos, independentemente das barreiras jurisdicionais. $\mathrm{O}$ tamanho dessa estrutura deve ser dimensionado de acordo com as necessidades de resposta ante o tipo de emergência ou desastre; porém, possui considerável flexibilidade interna, podendo crescer ou diminuir para atender às diferentes necessidades. Essa flexibilidade torna o gerenciamento mais econômico e eficiente para pequenas e grandes situações. Assim, equipes com qualquer combinação de recursos, únicos ou de diferentes classes, podem ser agregadas de forma a atender a um processo de comando e controle ${ }^{30}$.

No ICS, para que não haja perda de controle nas ações operacionais, cada profissional envolvido no incidente não se reporta a um grande número de pessoas. Assim, um líder possui um limite de cinco a sete pessoas sob a sua supervisão. Outro ponto importante é a integridade das comunicações, isto é, existe um plano único de comunicação entre todas as agências, com a utilização de uma mesma terminologia, canais e frequências interconectadas.

No protocolo de comunicação, a extensão das redes de dados dependerá do porte e da complexidade do incidente. O plano contém as condições operacionais e administrativas que definem quem, com quem, de que forma, quando e meio que será efetivada. Esse detalhamento evita o congestionamento de transmissões, que gera problemas no desenvolvimento de resposta ao incidente ${ }^{\mathbf{3 1}}$.

Na rede de comando do ICS, estão integradas as funções coordenadas pelo Comandante de Incidente (IC) e seus assessores de segurança, informação pública, ligação e inteligência. Além disso, prevê a existência de seções de operações, logística, planejamento e administração/finanças, para a coordenação de tarefas específicas destinadas à resolução do incidente e da gestão da informação e comunicação de $\operatorname{risco}^{32}$ (figura 1). 
Figura 1. Rede de comando do Sistema de Comando de Incidentes (ICS)

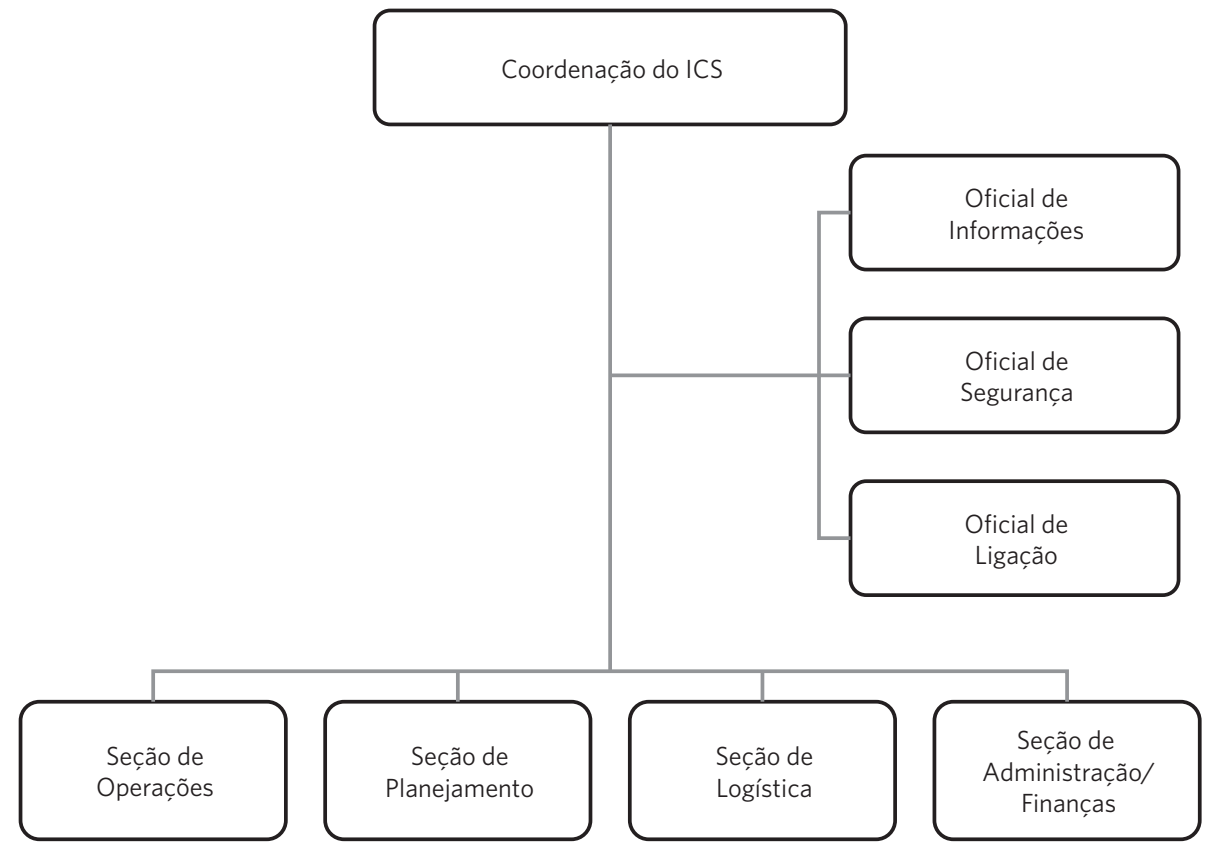

Fonte: Adaptado de Brasi|32

\section{Coordenação}

O coordenador define os objetivos e as prioridades do incidente e tem responsabilidade geral no evento, bem como pela segurança do Cien. É responsável pelo gerenciamento da informação e da formulação da comunicação de risco a ser disponibilizada ao Oficial de Informações Públicas (OIP). O IC também é responsável pelo estabelecimento e manutenção do contato com todas as agências participantes do incidente.

Inicialmente, a atribuição de recursos táticos e a supervisão das operações estarão sob sua supervisão direta. Ele possui uma equipe composta de secretários que auxiliam na preparação e registro de reuniões e outras atividades de assessoria direta.

O coordenador possui um subcoordenador, munido com as mesmas qualificações, com o qual deve operar conjuntamente, substituindo-o quando necessário.

\section{Oficial de Informações Públicas}

O OIP é o assessor de informação pública, sendo encarregado da divulgação das informações à população, organizações e autoridades, incluindo a mídia, que buscam informações do incidente.

O OIP procura obter dados sobre o evento, sua localização, horas de seu início, causa, existência de vítimas, medidas imediatas tomadas e ações estabelecidas para o controle da situação. É encarregado de preparar um informativo sobre a situação de funcionamento, dificuldades e ameaças ao Cien, e esses dados devem ser informados periodicamente ao coordenador, que estabelecerá as bases para as ações de planejamento e execução na gestão da informação. Estas informações auxiliam tanto na orientação da população quanto na condução da mídia no emprego de informações oficiais em suas reportagens, reduzindo o risco de rumores 
e apoiando o controle do pânico ${ }^{33}$. Dessa forma, é importante que o OIP seja objetivo, simples e conciso, utilizando uma linguagem com um mínimo de termos técnicos, para não provocar ruído na comunicação; atenha-se aos fatos e não realize inferências, potencializando o entendimento e a propagação da mensagem ${ }^{\mathbf{3 4}}$.

Embora o OIP concentre toda a governança das informações do incidente, assessorando o coordenador, existe uma equipe de comunicação que o apoia na captura, processamento, elaboração e geração da informação, em suas diferentes etapas.

\section{Oficial de Segurança}

O Oficial de Segurança é responsável pela condução das análises de risco e pela implementação de medidas de mitigação. Ele avalia e monitora as condições de segurança do local, fiscaliza e desenvolve ações para garantir a segurança do pessoal envolvido.

Ademais, aconselha o IC nas questões relacionadas com a segurança do incidente e trabalha em consonância com a Seção de Operações para garantir a segurança o tanto quanto possível, dadas as circunstâncias, incluindo o uso de equipamentos de proteção adequados e a implementação de opções táticas mais seguras.

O Cien é um lugar sensível, em que informações de segurança trafegam de modo oral, escrito e por infovias. Dessa forma, espaços específicos devem ser destinados aos representantes da mídia, distintos daquele nos quais a informação é trabalhada.

O Centro também é alvo de grupos que não compreendem o trabalho ali desenvolvido, sendo espaço passível de ações de furto de informações, revolta ou contenda. O Oficial de Segurança deve prever tais situações pelo uso de inteligência e segurança física, para tanto, deve instituir sistemas de credenciamento, controle de acesso, além de agentes e sistemas de segurança.

\section{Oficial de Ligação}

Faz a ligação entre o coordenador do Cien e o OIP. O oficial de ligação é o contato principal entre os representantes dos órgãos de apoio envolvidos e o coordenador. Ele oferece um resumo de informações (briefing) aos representantes, resolvendo dúvidas e quaisquer preocupações sobre a operação; além de filtrar o acesso, sem perder a qualidade da demanda que o agente possa produzir.

\section{Seção de Operações}

É responsável pelo desenvolvimento e pela implementação de estratégias e ações necessárias para alcançar os objetivos estabelecidos no plano de comunicações. Isso significa organizar, atribuir e monitorar todos os recursos de campo táticos atribuídos a um incidente, incluindo operações aéreas. Portanto, a maioria dos recursos de incidentes é atribuída à Seção de Operações.

Deve ser dirigida por um profissional com conhecimento técnico e tático para lidar com o problema em questão.

A seção deve ser organizada em segmentos, divididos em ramos de informação: imprensa escrita, televisiva, rádio, infovias, controle de rumores, inteligência, concatenação de dados, produção de informação pública e produção de informação para autoridades governamentais.

\section{Seção de Planejamento}

A Seção de Planejamento é responsável pela coleta, análise e disseminação de informações e inteligência. Além disso, projeta os dados relativos à comunicação e ao gerenciamento de risco. Essa seção trabalha em estreita colaboração com o IC para ter certeza de que as informações são compartilhadas com eficácia e resultam em um processo de planejamento eficiente para atender às necessidades do comandante e das operações. Isso inclui avaliar as informações correntes, prever eventos futuros, preparar estratégias alternativas para a seleção 
a serem tomadas pelo coordenador, mantendo atualizado o status dos recursos, documentando as atividades, respondendo inclusive por um plano para a desmobilização progressiva, a ser realizado quando o efetivo não for mais necessário para a operação.

Essa seção é dirigida por um chefe e é formada pelos ramos de recursos, situação, documentação e desmobilização, podendo ainda empregar especialistas técnicos para satisfazer alguma necessidade tático-estratégica específica. Responde ainda pela avaliação da situação e prognóstico, para definir a necessidade de pessoal e de materiais.

\section{Seção de Logística}

É responsável pelo apoio ao plano tático de gerenciamento e comunicação de risco. É composta pelos ramos de suporte de recursos e de serviços, apoiando as atividades de atendimento ao incidente. Realiza suas funções por meio da solicitação de todo o material e pessoal necessários, distribuição, armazenamento e registro dos recursos utilizados, estabelecimento de instalações para descanso, alimentação e manutenção, e promoção de serviços, tais como: abastecimento, reparo e transporte; estabelecimento de um sistema de comunicação e de apoio à unidade de saúde e para os integrantes das equipes de trabalho do Cien.

A Seção de Logística e a Seção de Administração e Finanças têm que trabalhar em conjunto para contratar bens e serviços necessários ao apoio ao incidente.

Inicialmente, as funções logísticas se concentram em única pessoa, porém, com o desenvolvimento do incidente, subunidades devem ser acrescidas à estrutura inicial, estabelecendo assim os ramos de suporte e de serviços. Esses ramos são supervisionados pela chefia da logística.

O ramo de suporte é composto pela unidade de suprimento e pela unidade de instalações. A unidade de suprimento é responsável por solicitar, armazenar, processar e fornecer todos os recursos relativos ao gerenciamento e comunicação de risco, tais como recursos táticos, de apoio (inclusive pessoal) e materiais de consumo. Já a unidade de instalações é responsável por construir, manter e desmobilizar as instalações usadas no apoio às operações, bem como pelo serviço de segurança. Essa unidade estabelece o ambiente da sala de crise, de comunicações e de todas as outras instalações (redes, equipamentos dos diferentes tipos de mídia, sala de estar, sala de imprensa, dormitórios e sanitários), de preferência aproveitando estruturas já existentes. Pode haver a necessidade da instalação de uma outra unidade para apoio às operações: como a de transporte, para o controle de viaturas.

O ramo de serviços é responsável pelas unidades de comunicação, de alimentação e de saúde. A unidade de comunicação tem como atividades o desenvolvimento de planos para a utilização mais efetiva e eficiente dos equipamentos de comunicações, testagem dos equipamentos de comunicação, distribuição e registro dos equipamentos, comunicabilidade das redes e frequências de uso. A unidade de alimentação é responsável pelo estabelecimento das instalações da cozinha, requisição dos gêneros alimentícios, cardápio, preparação e distribuição das refeições, bem como pela conservação dos alimentos. Ela deve planejar e antecipar as necessidades, tanto em número de refeições quanto ao local mais adequado de distribuição; por essa razão, trabalha articulada com a Seção de Planejamento, bem como com a unidade de instalações. Por outro lado, a unidade de saúde é responsável pelo desenvolvimento dos procedimentos e rotinas de assistência às ocorrências de saúde ocorridas no Cien, planejamento do transporte e socorro para os doentes, além do controle do processamento dos registros e documentações relativas aos acidentes e doenças.

\section{Seção de Administração e Finanças}

É estabelecida para gerenciar os serviços financeiros, respondendo pela análise de custos de um incidente. Isso inclui negociação e 
monitoramento de contratos, rastreamento de tempo dos recursos, tais como pessoal e equipamento; controle da documentação, processamento e compensação dos acidentes ou dos danos materiais ocorridos durante o incidente.

Possui uma relação direta com a Seção de Logística, no sentido de garantir a contratação e/ou aquisição de todos os recursos necessários para gerenciar o incidente.

Esta Seção pode estabelecer unidades de acordo com a amplitude e gravidade do incidente, número de agências envolvidas e necessidade financeira gerada. São unidades de tempo, aquisição e custo.

A unidade de tempo deve assegurar que o registro diário do tempo de serviço do pessoal está sendo preparado em conformidade com as exigências próprias dos respectivos órgãos. Se possível, o tempo das atividades será coletado após cada período operacional. O líder da unidade de tempo poderá contar com auxiliares afins com a política de contagem de tempo dos diferentes órgãos envolvidos. Os registros deverão ser checados; e as horas excessivas, declaradas em registro separado.

A unidade de aquisição responde pela operação de todas as questões financeiras pertinentes às compras e contratos. Articulase com os fornecedores locais, prepara e assina os contratos.

A unidade de custo responde pela promoção e avaliação de custos do incidente, assegurando o registro de todos os recursos. Com esses dados, prepara uma análise de custo, fazendo, inclusive, estimativas dos custos em caso de prolongamento das atividades da operação.

\section{Considerações finais}

A modelagem proposta neste estudo para o Cien, relacionado com a Central Nuclear Almirante Álvaro Alberto, trabalha com a hipótese de que é possível introduzir um modelo de comando unificado na gestão da informação, em que o coordenador do Centro de Informação institui as divisões existentes no ICS para gerir a governança do processo.

O ICS é um sistema de gerenciamento comprovado, com base em práticas bem-sucedidas, resultado de décadas de lições aprendidas na organização e gerenciamento de emergências e incidentes.

Considerando que acidentes nucleares têm uma probabilidade muito baixa de ocorrer, o método pretendido para a validação desse modelo seria realizado a partir de exercícios de emergência nuclear, que atualmente são realizados sistematicamente no Complexo Nuclear de Angra dos Reis, no estado do Rio de Janeiro.

A memória de dados existente de exercícios de emergência de anos anteriores seria a base de dados para a medição de melhoria do sistema de resposta e os indicadores de desempenho a serem utilizados.

Para enfrentar os desafios, o modelo necessita ser essencialmente interdisciplinar, uma vez que integra diversas agências, organizações e instituições em torno de uma estrutura de gerenciamento comum, garantindo que a equipe operacional possa atender aos objetivos táticos por meio do fornecimento de suporte logístico e administrativo à área operacional e do uso eficiente dos recursos disponibilizados, evitando duplicação de esforços.

A flexibilidade inerente à ferramenta faz com que ela possa expandir ou contrair para atingir as diferentes necessidades impostas pelo evento ao qual está se atendendo. Dessa forma, entre os resultados esperados no modelo proposto, encontra-se a possibilidade de seu uso, tanto do ponto de vista do custo operacional quanto do ponto de vista da eficiência da abordagem gerencial, em qualquer situação, complexa ou simples, independentemente do seu tipo ou magnitude, sejam rotineiros ou planejados, como conferências, shows e grandes jogos, ou em incidentes de grandes proporções, como desastres, acidentes químicos industriais, surtos de doenças e atos de terrorismo. 


\section{Colaboradores}

Santos MTR (0000-0003-0801-9067)*, Silva MVC (0000-0001-7461-0109)* e Cardoso TAO (0000-0002-5430-7273)* contribuíram igualmente para a concepção, levantamento de dados, elaboração do rascunho e da redação, revisão crítica do conteúdo e aprovação da versão final do manuscrito.

\section{Referências}

1. Ha-Duong M, Journé V. Calculating nuclear accident probabilities from empirical frequencies. Env. Syst. Decisions. 2014; 34(2):249-58.

2. International Atomic Energy Agency. IAEA TECDOC $\mathrm{n}^{\circ}$ 955. Generic assessment procedures for determining protective actions during a reactor accident [internet]. Vienna: IAEA; 1997. [acesso em 2019 mar 10]. Disponível em: https:/www-pub.iaea.org/MTCD/ publications/PDF/te_955_prn.pdf.

3. Baverstock K, Williams D. O acidente de Chernobyl 20 anos depois: avaliação das consequências e resposta internacional. Ciênc. Saúde Colet. 2007; 12(3):68998.

4. International Atomic Energy Agency. The International Nuclear and Radiological Event Scale. User's Manual. Viena: IAEA; 2013.

5. Walker JM. Three Mile Island. A Nuclear Crisis in Historical Perspective. Berkeley: University of California; 2004.

*Orcid (Open Researcher and Contributor ID).
6. US Nuclear Regulatory Commission. Lessons learned from the Three Mile Island-Unit 2. Advisory Pa- nel. NUREG/CR-6252 [internet]. Washington: NRC; 1994. [acesso em 2019 mar 8]. Disponível em: https:// tmi2kml.inl.gov/Documents/2c-L2-NUREG/NUREGCR-6252,\%20Lessons\%20Learned\%20from\%20 the\%20TMI-2\%20Advisory\%20Panel\%20(1994-08). pdf.

7. Sandman PM. Tell it like it is. IAEA Bulletin. 2006; 47(2):9-14.

8. Becker MT. Emergency communication and information issues in terrorist events involving radioactive materials. Biosecur Bioterror. 2004; 2(3):195-203.

9. Collins DL, Baum A, Singer JE. Coping with chronic stress at Three Mile Island: psychological and biochemical evidence. Health Psyc. 1983; 2(2):149-66.

10. Tronea M, Ciurea C. Nuclear safety culture attributes and lessons to be learned from past accidents. Intern Nuclear Safety J. 2014; 3(3):1-7.

11. International Atomic Energy Agency. INSAG-7. The Chernobyl Accident: updating of INSAG-1. A report by the international nuclear safety advisory group. Safety Series n0 75-INSAG-7 [internet]. Vienna: IAEA; 
1992. [acesso em 2019 fev 27]. Disponível em: https:// www-pub.iaea.org/MTCD/publications/PDF/Pub913e_web.pdf.

12. Tuttle RM, Becker DV. The Chernobyl accident and its consequences: update at the millennium. Semin Nucl Med. 2000; 30(2):133-40.

13. Rubin DM. How the News media reported on Three Mile Island and Chernobyl. J Communication. 1987; $37(3): 42-57$.

14. International Atomic Energy Agency. Radiological accident in Goiania [internet]. Vienna: IAEA; 1988. [acesso em 2019 fev 27]. Disponível em: https://www-pub.iaea.org/MTCD/publications/PDF/Pub815_web. pdf.

15. Curado MP. The communication of radiological risk to populations exposed to a radiological accident: considerations concerning the accident in Goiânia. Radiat Prot Dosim. 1996; 68(3-4):283-6.

16. Helou S, Costa Neto SB. Césio-137: história do acidente e atuação da psicologia. In: Helou S, editor. Césio-137: consequências psicossociais do acidente de Goiânia. 2. ed. Goiância: UFG; 2014. p. 13-29.

17. Palestino CSF, Dias FP. Aspectos sociais dos vinte anos desde o acidente radiológico com césio-137. In: Helou S. editor. Césio-137: consequências psicossociais do acidente de Goiânia. 2. ed. Goiânia: UFG; 2014. p. 120-33.

18. Lipscy P, Kushida K, Incerti T. The Fukushima disaster and Japan's nuclear plant vulnerability in comparative perspective. Environ Sci Technol. 2013; 47(12):60828.

19. Ohnishi T. The disaster at Japan's Fukushima-Daiichi nuclear power plant after the March 11, 2011 earthquake and tsunami, and the resulting spread of radioisotope contamination. Radiat Res. 2012; 177(1):1-14.

20. Kortov V, Ustyantsev Y. Chernobyl accident: Causes, consequences and problems of radiation measurements. Radiat Meas. 2013; (55):12-6.
21. Imanaka T, Hayashi G, Endo S. Comparison of the accident process, radioactivity release and ground contamination between Chernobyl and Fukushima-1. J Radiat Res. 2015; 56(suppl1):i56-61.

22. Saskawa Peace Foundation. The Fukushima nuclear accident and crisis management. Lessons for Japan-US alliance cooperation. Tokyo: SPF; 2012.

23. De Marchi B. The Sevezo Directive: an Italian pilot study in enabling communication. Risk Anal. 1991; 11(2):207-15.

24. Aakko E. Risk communication, risk perception and public health. WMJ. 2004; 103(1):25-7.

25. Fisher A. Risk Communication Challenges. Risk Anal. 1991; 11(2):173-9.

26. Bradbury JA. The policy implications of differing concepts of risk. Sci Technol Hum Values. 1989; 14(4):380-99.

27. Brasil. Secretaria de Assuntos Estratégicos. Portaria $n^{\circ}$ 27, de 27 de março de 1997. Aprova a norma geral que dispõe sobre a instalação e o funcionamento dos centros encarregados da resposta a uma situação de emergência nuclear. Diário Oficial da União. 31 Mar 1997.

28. Brasil. Lei ${ }^{\circ} 12.731$, de 21 de novembro de 2012. Institui o Sistema de Proteção ao Programa Nuclear Brasileiro - SIPRON e revoga o Decreto Lei no 1.809, de 7 de outubro de 1980. Diário Oficial da União. 22 Nov 2012.

29. Federal Emergency Management Agency. ICS-0200.c Basic incident command system for initial response, ICS 200. Washington, DC: FEMA; 2019.

30. Federal Emergency Management Agency. Incident Management Handbook: B-761 Interim. Washington, DC: FEMA; 2010.

31. International Fire Service Trainning Association. Essentials of Fire Fighting and Fire Department Operations. 6. ed. Stillwater: Fire Protection Publications; 2013. 
32. Brasil. Ministério da Integração Nacional. Secretaria Nacional de Defesa Civil. Sistema de Comando em Operações. Florianópolis: UFSC; 2010.

33. Deal T, Bettencourt M, Deal V, et al. Beyond Initial Response: using the National Incident Management System's Incident Command System. 2. ed. Bloomington: Author House; 2012.
34. Spiegelhalter D. Risk and Uncertainty Communication. Annu. Rev Stat. Appl. 2017; 4(1):31-60.

Recebido em 29/08/2019

Aprovado em 29/02/2020

Conflito de interesses: inexistente

Suporte financeiro: não houve 